\title{
The Pay Dispersion within Top Managers and Corporate Environmental Responsibility Information Disclosure
}

\author{
Gan Shengdao ${ }^{1}$, Mo Wenyu*2 \\ ${ }^{1}$ Business School, Sichuan University, Chengdu, Sichuan, China \\ ${ }^{2}$ Business School, Sichuan University, Chengdu, Sichuan, China
}

\begin{abstract}
Because of the large scale of listed companies, they are often the main responsible parties for environmental problems. Therefore, from the perspective of compensation incentive, this study made an empirical test on how the pay dispersion within top managers affects corporate environmental responsibility information disclosure. By selecting A-share companies listed in Shanghai or Shenzhen Stock Exchange which published corporate social responsibility reports from 2008 to 2018 as research samples, a multivariate regression analysis model was established. The results showed that there is a significant inverted U-shaped relationship between executive compensation gap and corporate environmental responsibility information disclosure. Further research found that this relationship was only significant in state-owned enterprises.
\end{abstract}

\section{Introduction}

Environmental protection has always been a topic of great concern. As an important part of social operation, enterprises have a great impact on the environment because of their large consumption of resources. Therefore, in the context of emphasizing green development, it is of great practical significance to promote enterprises to establish a transparent environmental responsibility information disclosure system. On the other hand, for enterprises, the disclosure of environmental responsibility information can increase their information transparency, improve their reputation, and then reduce their financing costs [1] [2], which has an important impact on the value of enterprises [3]. However, existing studies have shown that Chinese enterprises lack the motivation to disclose environmental information or improve environmental performance [4]. Therefore, it is necessary to take measures to promote enterprises to disclose environmental information actively.

As the executor of corporate affairs, the senior managers are responsible for making corporate environmental responsibility information disclosure decisions, and are responsible for its implementation effect. According to the principal-agent theory, enterprise owners need to take incentives and other measures to restrain the self-interested behavior of enterprise managers, so as to make the interests of executives and enterprise owners converge as much as possible. One of the important incentive means is to make reasonable arrangement of the pay gap among senior managers. As for the incentive principle of internal pay gap within executives, there are mainly two hypotheses in theory, namely the tournament theory and the fairness theory.
According to the tournament theory, the larger the compensation gap among executives is, the greater the incentive effect on corporate executives will be. The attractive compensation gap will motivate senior managers at all levels to achieve performance goals and increase the possibility of job promotion. However, equity theory believes that too large compensation gap among senior executives is not conducive to the internal collaboration of senior managers, and even makes senior executives slow down due to their feelings of injustice, which ultimately leads to decision-making failure and damages the interests of the enterprise. Then, will the compensation gap among top managers affect the environmental responsibility information disclosure of enterprises? Relevant studies have found that, based on the compensation justification, the excess compensation of executives is positively correlated with the quality of environmental information disclosure [5]. However, there is still a lack of research on the relationship between the pay dispersion within executives and corporate environmental responsibility disclosure.

Based on the above analysis, the problem studied in this paper is how the pay dispersion within top managers will affect the environmental responsibility information disclosure of enterprises. The possible contributions of this paper are as follows: it studies the influence of the internal incentive system of enterprises on the environmental responsibility information disclosure, enriches the research literature in this field. And it is of great significance to promote the disclosure of environmental responsibility information of enterprises and help to realize the goal of green development. 


\section{Materials and Methods}

\subsection{Data Sources and Sample Selection}

This study employed A-share companies listed in Shanghai or Shenzhen Stock Exchange which published corporate social responsibility reports from 2008 to 2018 as research samples. And excluded the financial sector, ST and ${ }^{*}$ ST listed companies. Samples containing missing values were deleted and all continuous variables were winsorized by $1 \%$ on both sides. We ended up with 3,081 observations from 575 companies. The data used in this study were collected from China Stock Market Accounting Research Database(CSMAR). And the data was analyzed and processed using STATA15.

\subsection{Definition of Variables}

Dependent variable: corporate environmental responsibility information disclosure. The number of environmental and sustainable development projects disclosed in the social responsibility report published by the enterprise is used for measurement, and the symbol is Cer2w.

Independent variable: the pay dispersion within top managers. It is measureed by the natural logarithm of the difference between the average pay of the top three executives and the average pay of other executives, and symbolized as InegapA. In addition, in the robustness test, we replaced its measurement as: the natural logarithm of the difference between the average compensation of the first ranked executive and the average compensation of other executives, symbolized as InegapB.

Control variables: Based on the existing research on corporate environmental responsibility information disclosure, this study selected enterprise scale, capital structure, the proportion of independent directors, corporate profitability, net interest rate on operating income, dual role of the board chairman as control variables. The specific definitions of all variables used in this study are shown in Table I.

Table I. definition of variables

\begin{tabular}{|c|c|c|}
\hline Variable & Symbol & Definition \\
\hline $\begin{array}{l}\text { Corporate environmental responsibility } \\
\text { information disclosure }\end{array}$ & Cer2w & $\begin{array}{c}\text { Number of environmental and sustainable development projects } \\
\text { published in corporate social responsibility reports }\end{array}$ \\
\hline \multirow{2}{*}{ The pay dispersion within top managers } & InegapA & $\begin{array}{c}\text { The natural logarithm of the difference between the average pay of the } \\
\text { top three and that of other top executives }\end{array}$ \\
\hline & InegapB & $\begin{array}{l}\text { The natural logarithm of the difference between the average pay of the } \\
\text { top one and that of other top executives }\end{array}$ \\
\hline Enterprise size & Size & Natural logarithm of total assets on the balance sheet \\
\hline Capital structure & Capstru & Total liabilities/total assets \\
\hline The proportion of independent directors & Inbp & Number of independent directors/total number of directors \\
\hline Corporate profitability & Roe & Net profit/average net assets \\
\hline Net interest rate on operating income & Smargin & Net profit/operating revenue \\
\hline Dual role of the board chairman & Dual & $\begin{array}{l}\text { The Chairman of the Board and the General Manager are the same } \\
\text { person, take } 1 \text {, otherwise take } 0\end{array}$ \\
\hline Year & Year & Year dummy \\
\hline Industry & Industry & Industry dummy \\
\hline
\end{tabular}

\subsection{Regression Model}

After several tests, the empirical model finally adopted in this study is as follows. According to the results of the Hausman test, we adopted the fixed effect model of panel data, and controled the fixed effect of year and industry. Robust standard error was adopted for regression in this study.

Cer $2 w_{i, t}=\alpha_{0}+\alpha_{1}$ Inegap $_{i, t}+\alpha_{2}{\text { Inegap } A 2_{i, t}}+\alpha_{j}$ Controls $_{i, t}$ $+\sum$ Year $+\sum$ Industry $+\varepsilon_{i, t}$

Where InegapA2 represents the square term of InegapA; Controls represents all the control variables in the table1; $\sum$ Year and $\sum$ Industry represent Year fixed effect and Industry fixed effect respectively, and $\varepsilon_{i, t}$ represents stochastic disturbance.

\section{Results \& Discussion}

\subsection{Descriptive Statistics}

Table II reports the descriptive statistics of the main variables used in this study. The minimum value of Cer $2 \mathrm{w}$ is 1 , the maximum value is 72 , and the standard deviation is 11.31 , indicating that the environmental responsibility disclosure level of sample enterprises is greatly different. The median value of Cer $2 \mathrm{w}$ is less than the mean value, which indicates that the overall environmental disclosure level of sample enterprises is not high. The standard deviation of InegapA and InegapB is 12.92 and 12.76 respectively, indicating that the sample companies have a large discrepancy in the arrangement of the pay gap within the top management team. It shows that listed companies in China still have a large space to use the incentive tool of the pay gap within the top management team. The statistics of other control variables are not abnormal.

Table II. Descriptive statistics

\begin{tabular}{ccccccc}
\hline variable & $\mathbf{N}$ & mean & sd & min & p50 & max \\
\hline Cer2w & $3,081.00$ & 8.29 & 11.31 & 1.00 & 4.00 & 72.00 \\
InegapA & $3,081.00$ & 12.92 & 0.81 & 1.10 & 12.86 & 16.53 \\
InegapB & $3,081.00$ & 12.76 & 0.96 & 0.00 & 12.66 & 16.49 \\
Size & $3,081.00$ & 22.82 & 1.37 & 18.76 & 22.71 & 28.25
\end{tabular}




\begin{tabular}{ccccccc} 
Capstru & $3,081.00$ & 0.40 & 0.18 & 0.03 & 0.42 & 0.65 \\
Roe & $3,081.00$ & 0.09 & 0.11 & -0.52 & 0.09 & 0.39 \\
Smargin & $3,081.00$ & 4.96 & 27.32 & - & - & \\
Inbp & $3,081.00$ & 0.37 & 0.06 & 0.13 & 0.11 & 205.23 \\
Dual & $3,081.00$ & 0.17 & 0.37 & 0.00 & 0.00 & 0.80 \\
\hline
\end{tabular}

\subsection{Data Correlation Analysis}

The correlation coefficients for the main variables used in this study are reported in Table III. The pay gap within the top management team is positively correlated with corporate environmental responsibility information disclosure, indicating that the compensation gap among executives will have an impact on corporate environmental responsibility information disclosure behavior. The detailed analysis is reported in the empirical test results section.

Table III. CORRELATION COEFFICIENTS

\begin{tabular}{|c|c|c|c|c|c|c|c|c|c|}
\hline & Cer2w & InegapA & InegapB & Size & Capstru & Roe & Smargin & Inbp & Dual \\
\hline Cer2w & 1.000 & & & & & & & & \\
\hline InegapA & $0.099 * * *$ & 1.000 & & & & & & & \\
\hline InegapB & $0.090 * * *$ & $0.949 * * *$ & 1.000 & & & & & & \\
\hline Size & $0.334 * * *$ & $0.278 * * *$ & $0.232 * * *$ & 1.000 & & & & & \\
\hline Capstru & $0.096 * * *$ & $0.037 * *$ & $0.035^{*}$ & $0.384 * * *$ & 1.000 & & & & \\
\hline Roe & -0.010 & $0.257 * * *$ & $0.227 * * *$ & $0.034 *$ & $-0.129 * * *$ & 1.000 & & & \\
\hline Smargin & 0.030 & $0.066 * * *$ & $0.050 * * *$ & 0.020 & $-0.087 * * *$ & $0.060 * * *$ & 1.000 & & \\
\hline Inbp & 0.000 & 0.020 & 0.010 & $0.117 * * *$ & 0.020 & 0.000 & -0.010 & 1.000 & \\
\hline Dual & $-0.061 * * *$ & $0.116 * * *$ & $0.174 * * *$ & $-0.084 * * *$ & $-0.077 * * *$ & $0.073 * * *$ & -0.020 & $0.084 * * *$ & 1.000 \\
\hline
\end{tabular}

\subsection{Effect of the Pay Dispersion within Top Managers on Corporate Environmental Responsibility Information Disclosure}

The first column of Table IV is the regression result of applying model (1) to test the research questions of this paper. It can be seen from the regression coefficient that there is not a linear relationship between the pay dispersion within top managers and corporate environmental responsibility information disclosure, but an inverted U-shaped relationship significant at the $1 \%$ level. It shows that with the increase of the pay gap within the top management, the environmental responsibility information disclosure will be promoted at first, and when the gap is too large, the environmental responsibility information disclosure behavior will be restrained. This result reveals that the bigger the compensation gap among executives is not the better, that is, there is a most effective gap level to motivate executives to actively fulfill the obligation of environmental responsibility information disclosure. Enterprises should find and make full use of the incentive tool of compensation gap among senior managers in practice, responding to the government's call for green development, and better fulfill their environmental responsibility obligations.

\subsection{Robustness Test}

Change the measure of the independent variable: In order to test whether the empirical results of this study are robust, we replaced the measure of the independent variable. The regression results are reported in the second column of Table IV. Obviously, the regression results are consistent with the conclusion of this study, that is, the conclusion of this study is robust.

Advance the dependent variable by one period to avoid endogenous problem: In order to control the possible endogeneity problem, we applied the model (1) for regression analysis after one period advancement to the dependent variable, and the regression results are reported in the third column of Table IV. It can be seen that the regression results are still robust.

Table IV. Results of multivariate regression analysis

\begin{tabular}{cccc}
\hline \hline & $(\mathbf{1})$ & $\mathbf{( 2 )}$ & $\mathbf{( 3 )}$ \\
& $\mathbf{C e r 2 w}$ & $\mathbf{C e r 2 w}$ & $\mathbf{F . C e r 2 w}$ \\
\hline InegapA & $2.68^{* * *}$ & & $3.86^{* * *}$ \\
& {$[0.58]$} & & {$[0.73]$} \\
InegapA2 & $-0.11^{* * *}$ & & $-0.16^{* * *}$ \\
& {$[0.04]$} & & {$[0.05]$} \\
InegapB & & $2.36^{* * *}$ & \\
& & {$[0.38]$} & \\
InegapB2 & & $-0.10^{* * *}$ & \\
& & {$[0.02]$} & \\
Size & $2.14 * *$ & $2.17 * *$ & 0.97 \\
& {$[0.99]$} & {$[0.99]$} & {$[0.91]$} \\
Capstru & 0.22 & 0.22 & 1.73 \\
& {$[2.14]$} & {$[2.14]$} & {$[2.30]$} \\
Roe & 1.07 & 1.08 & 2.57 \\
& {$[1.93]$} & {$[1.93]$} & {$[1.64]$} \\
Smargin & $-0.01 *$ & $-0.01 *$ & -0.00 \\
& {$[0.01]$} & {$[0.01]$} & {$[0.01]$} \\
Inbp & $-12.17 * *$ & $-12.16^{* *}$ & -2.19 \\
& {$[5.49]$} & {$[5.52]$} & {$[5.54]$} \\
Dual & 0.15 & 0.17 & 0.64 \\
& {$[0.51]$} & {$[0.52]$} & {$[0.59]$} \\
cons & $-52.22^{* *}$ & $-50.48^{* *}$ & $-37.46^{*}$ \\
& & &
\end{tabular}




\begin{tabular}{cccc} 
& {$[23.12]$} & {$[22.81]$} & {$[21.88]$} \\
\hline $\mathrm{N}$ & 3081.00 & 3081.00 & 2930.00 \\
year & Yes & Yes & Yes \\
Industry & Yes & Yes & Yes \\
r2-a & 0.57 & 0.57 & 0.57 \\
$\mathrm{~F}$ & 12.30 & 14.69 & 10.24 \\
\hline \hline
\end{tabular}

t statistics in parentheses, $* * * 1 \% * * 5 \% * 10 \%$

\subsection{The Heterogeneity Test on the Nature of Property Rights}

Different from non-state-owned enterprises, state-owned enterprises pay more attention to the implementation of environmental responsibility in the performance appraisal system for senior executives. Therefore, it is not difficult to predict that in state-owned enterprises, executive compensation incentives will have a more significant impact on corporate environmental responsibility information disclosure. Based on the above analysis, the sample enterprises are grouped according to the nature of property rights, and the model (1) is applied to further test the relationship between the pay dispersion within top managers and corporate environmental responsibility information disclosure. The regression results are shown in Table $\mathrm{V}$. The results show that there is an inverted Ushaped relationship between the pay gap within top managers and corporate environmental responsibility information disclosure in state-owned enterprises, and it is significant at the $1 \%$ level. In the sample of non-stateowned enterprises, there is no significant correlation. This result has a certain enlightenment effect -- to promote nonstate-owned enterprises to disclose environmental responsibility information more actively, we can guide them to include environmental responsibility in the assessment indicators to the top management, and use the internal compensation gap of senior executives to motivate them to fulfill their environmental responsibility obligations.

\section{Conclusions}

Based on 3,081 observation data from 575 Shanghai and Shenzhen A-share listed companies that have published corporate social responsibility reports, this study examined the relationship between the pay gap within top managers and environmental responsibility information disclosure through multivariate regression analysis. After robustness test, we obtained a relatively robust empirical result, that is, there is an inverted U-shaped relationship between the pay gap within top managers and environmental responsibility information disclosure, and it is significant at the level of $1 \%$. On this basis, the grouping test results of the nature of property rights show that the inverted U-shaped correlation only exists significantly in state-owned enterprises. This conclusion suggests that the incentive effect of the pay gap within executives is respectively applicable to the tournament theory and the equity theory in different intervals. In other words, there is a most reasonable and effective level of compensation gap, and under the incentive of this reasonable compensation gap, enterprises disclose the most environmental responsibility information. In addition, non-state-owned enterprises seldom include environmental responsibility performance in the evaluation system of senior managers, which results in the incentive effect of the pay gap among senior managers on environmental responsibility information disclosure can not be effectively exerted. Policy makers can take measures to encourage companies to take environmental responsibility into account in executive compensation contracts, so as to activate the incentive effect of executive compensation gap on corporate environmental responsibility information disclosure, to promote the fulfillment of corporate environmental responsibility, and to promote Chinese enterprises to achieve the goal of transforming to green development.

Table V. Heterogeneity test on the nature of property right

\begin{tabular}{|c|c|c|}
\hline & $\begin{array}{c}\text { (1) } \\
\text { State-owned }\end{array}$ & $\begin{array}{c}\text { (2) } \\
\text { Non-state-owned }\end{array}$ \\
\hline InegapA & $\begin{array}{c}2.74 * * * \\
{[0.74]}\end{array}$ & $\begin{array}{c}-6.90 \\
{[20.05]}\end{array}$ \\
\hline InegapA2 & $\begin{array}{c}-0.12 * * \\
{[0.05]}\end{array}$ & $\begin{array}{c}0.22 \\
{[0.73]}\end{array}$ \\
\hline Size & $\begin{array}{c}1.46 \\
{[1.13]}\end{array}$ & $\begin{array}{l}3.33^{*} \\
{[1.70]}\end{array}$ \\
\hline Capstru & $\begin{array}{c}2.81 \\
{[2.68]}\end{array}$ & $\begin{array}{l}-5.60^{*} \\
{[3.23]}\end{array}$ \\
\hline Roe & $\begin{array}{c}1.75 \\
{[2.37]}\end{array}$ & $\begin{array}{c}0.04 \\
{[2.89]}\end{array}$ \\
\hline Smargin & $\begin{array}{c}-0.02 * * * \\
{[0.01]}\end{array}$ & $\begin{array}{c}-0.00 \\
{[0.01]}\end{array}$ \\
\hline Inbp & $\begin{array}{c}-17.00 * * * \\
{[6.40]}\end{array}$ & $\begin{array}{c}3.82 \\
{[9.35]}\end{array}$ \\
\hline Dual & $\begin{array}{l}-0.44 \\
{[0.71]}\end{array}$ & $\begin{array}{c}1.08 \\
{[0.66]}\end{array}$ \\
\hline cons & $\begin{array}{l}-35.56 \\
{[27.16]}\end{array}$ & $\begin{array}{c}-15.58 \\
{[132.45]}\end{array}$ \\
\hline $\mathrm{N}$ & 2038.00 & 1043.00 \\
\hline year & Yes & Yes \\
\hline Industry & Yes & Yes \\
\hline $\mathrm{r} 2-\mathrm{a}$ & 0.55 & 0.60 \\
\hline F & 23.10 & 1.13 \\
\hline
\end{tabular}

$\mathrm{t}$ statistics in parentheses, $* * * 1 \% * * 5 \% * 10 \%$

\section{References}

1. TONG, M. H., XU, D. Y., ZHENG, T. W. (2020). Environmental information disclosure and cost of equity capital: an analysis of the mediating effect based on information transparency and social responsibility. Research on Financial and Economic Issues, 02: 63-71.

2. Luo, W., Guo, X., Zhong, S., Wang, J. (2019). Environmental information disclosure quality, media attention and debt financing costs: evidence from 
Chinese heavy polluting listed companies. Journal of Cleaner Production, 231: 268-277.

3. Yang, Y., Wen, J., Li, Y. (2020). The impact of environmental information disclosure on the firm value of listed manufacturing firms: evidence from China. International Journal of Environmental Research and Public Health, 17(3).

4. Li, D., Zhao, Y., Sun, Y., Yin, D. (2017). Corporate environmental performance, environmental information disclosure, and financial performance: evidence from China. Human and Ecological Risk Assessment, 23(2): 323-339.

5. Li, Q., Li, T., Chen, H., Xiang, E., Ruan, W. (2019). Executives' excess compensation, legitimacy, and environmental information disclosure in Chinese heavily polluting companies: the moderating role of media pressure. Corporate Social Responsibility and Environmental Management, 26(1): 248-256. 